\title{
ANÁLISE SENSORIAL E TESTE DE ACEITAÇÃO DO QUEIJO DE COALHO PRODUZIDO COM LEITE CRU E PASTEURIZADO NA CIDADE DE CURRAIS NOVOS.
}

\author{
Maria Cecília Galdino de ARAÚJO; Ramon Araújo dos SANTOS; Cláudia Patrícia \\ Araújo e SILVA; Rayane de Lima CIRILO; Rayssa de Lima CIRILO; Regina Célia \\ Pereira MARQUES
}

IFRN - Campus Currais Novos. E-mail: regina.marques@cefetrn.br

\section{RESUMO}

Dentre os produtos de laticínios fabricados no nordeste, o queijo de coalho é um dos mais difundidos. Este produto possui grande popularidade e é fabricado principalmente nos estados do Rio grande do norte, Paraíba, Ceará e Pernambuco. (CALVACANTE; ANDRADE; SILVA; 2004). A fabricação e comercialização deste produto representam uma atividade de grande importância para a economia regional, sendo desenvolvido por uma parcela considerável de pequenos produtores estabelecidos principalmente na zona rural, significando sua principal fonte de renda. Os queijos produzidos a partir do leite cru apresentam em geral, uma grande quantidade de microorganismos responsáveis pela deterioração e/ou redução da vida útil, indicadores de más condições higiênicas - sanitárias do processamento, além da manipulação inadequada da matéria-prima, utensílios e equipamentos (MUNK, 2004). Além disso, por tradição ou por desconhecimento, o produto acaba sem qualquer padrão em relação às técnicas de processamento e qualidade do produto final. Por estes motivos o produto obtido possui qualidade microbiológica insatisfatória, com alto grau de contaminação, caracterizando-se como risco a saúde publica (JACK et al., 1993). Dada a grande importância deste produto para os seus consumidores, estudos comprovaram que os mesmos elaborados com leites pasteurizados tornam-o mais seguros em relação à saúde. Uma vez que a pasteurização reside basicamente no fato de se aquecer o alimento a determinada temperatura, e por determinado tempo, de forma a eliminar os microorganismos patogênicos. Além de minimizar ao máximo o numero de microorganismos em geral. (SCHIMITT, 2007). Deste modo, deram origem não só a um importante método de conservação, mais como também a uma medida higiênica fundamental para preservar a saúde dos consumidores e conservar a qualidade dos produtos alimentícios. Considerando o queijo de coalho mais consumido na região, torna-se importante conhecer a aceitabilidade dos queijos elaborados a partir do leite cru e pasteurizados. Sendo realizado teste de aceitação entre 50 pessoas de ambos os sexos e diferente faixa etária. Os resultados apontaram que $80 \%$ das pessoas preferiram o queijo feito com leite cru, indicando ser mais saboroso. Quanto ao fato de trocarem pelo consumo de queijo de coalho pasteurizado, apenas $15 \%$ falou que poderiam fazer a troca, a grande maioria disseram que continuarão consumindo o queijo tradicional.

PALAVRAS CHAVES: Leite pasteurizado, queijo coalho, microrganismos, leite cru. 


\section{ANÁLISE SENSORIAL E TESTE DE ACEITAÇÃO DO QUEIJO DE COALHO PRODUZIDO COM LEITE CRU E PASTEURIZADO NA CIDADE DE CURRAIS NOVOS.}

\section{INTRODUÇÃO}

A produção do queijo de coalho no nordeste do Brasil representa uma importante atividade na economia regional, principalmente para os pequenos e médios produtores rurais (ESCOBAR et al., 2001). Esse queijo tem destaque entre os principais queijos artesanais de fabricação e consumo da cultura regional; sendo habitualmente consumido assado ou frito (MUNCK, 2004). Devido às características de consumo e sabor, o queijo de coalho industrializado vem ganhando novos consumidores no sudeste do país (CAVALCANTE, 2005). Legalmente, o queijo de coalho é obtido por coagulação do leite com coalho ou outras enzimas coagulantes apropriadas, complementada ou não por ação de bactérias láticas selecionadas, sendo comercializado com até dez dias de fabricação. É classificado como queijo de massa semi-cozida ou cozida, de média a alta umidade e um teor de gordura nos sólidos totais entre $35,0 \%$ e 60,0\%. Sensorialmente deverá apresentar consistência semi-dura, elástica; textura macia, compacta ou aberta com olhaduras mecânicas pequenas; cor branca, amarelada e uniforme; sabor brando, ligeiramente ácido, podendo ser salgado; odor ligeiramente ácido de coalhada fresca; casca fina, sem trinca, não bem definida; formato e peso variáveis (BRASIL, 2001).

O queijo de coalho é um produto de grande expressão na região, sendo produzido em larga escala, tanto de forma artesanal como de forma industrial. Os queijos produzidos a partir do leite cru e em condições precárias de higiene apresentam riscos de toxinfecções alimentares. Por isso, faz-se necessária a utilização de tecnologias que prolonguem a sua vida útil já que é um produto facilmente perecível.

Com a descoberta da pasteurização por Pasteur, em 1863, pode-se empregar esse processo no beneficiamento do leite. A pasteurização não foi empregada imediatamente no leite, para isso foi necessário o desenvolvimento da refrigeração. Assim, a combinação da pasteurização com a refrigeração industrial, no final do século XIX, pode disponibilizar o leite de maneira mais eficiente em relação à conservação (LEITE et al., 2002).

A higiene do leite e derivados lácteos tem como objetivo básico assegurar a inocuidade dos produtos e saúde dos consumidores. A presença de certos microrganismos e suas toxinas constitui as causas mais freqüentes de problemas sanitários relacionados aos produtos lácteos. O leite e seus derivados, consumidos por muitos, não sofrem qualquer tipo de tratamento térmico como a esterilização e a pasteurização, podendo conter grandes quantidades de toxinas e microrganismos capazes de causar intoxicações alimentares (LEITE et al., 2002). Tal fato deve ser levado em consideração, principalmente porque os maiores consumidores de leite são crianças e idosos. O processo de pasteurização é necessário e eficiente, e tem por finalidade reduzir o número de microrganismos presentes no leite e eliminar os agentes patogênicos (LEITE et al., 2002). Além destas vantagens, o aquecimento a temperatura acima de $80^{\circ} \mathrm{C}$, também causa desnaturação das lactoglobulinas e lactoalbuminas, favorecendo o desenvolvimentos dos fermentos láticos, pois há melhor disponibilidade de nitrogênio protéico. 
O leite possui em sua microflora, contaminantes comuns, expressos em pequena quantidade, sendo os principais: Micrococcus, Streptococcus e Corynebacterium, alem de alguns lactobacilos saprófitas presentes no canal galactífero (SOUSA, 2005). Leite e colaboradores (2002) relatam que um dos grandes problemas do leite está relacionado com a quantidade de microrganismos, sendo que alguns desses estão presentes no momento da ordenha, outros são incorporados pela falta de higiene do ordenhador, utensílios mal higienizados e mesmo pelo próprio ambiente.

As bactérias têm maior expressão no que se refere à contaminação do leite, sendo leveduras e fungos menos comuns. Dentre os contaminantes estão às bactérias láticas, coliformes, Micrococcus, Staphilococcus, enterococos, Bacillus, esporos de Clostridium e bastonetes gram-negativos. Em condições normais de temperatura predominam as bactérias gram-positivas (SCHIMITT, 2007). O principal objetivo deste trabalho foi realizar análise sensorial e teste de aceitação de queijos de coalho produzido com leite cru e leite pasteurizado, com 50 pessoas residentes ao município de Currais Novos e produzidos na região do Seridó.

\section{METODOLOGIA}

1.Teste de aceitação de queijos coalho produzidos com leite cru (QCC) e leite pasteurizado (QCP). Foram tilizados 5 queijos industriais de marcas diferentes, com a garantia de selos de qualidade e 5 queijos artesanais de produtores diferentes da região do Seridó.

2.Para os testes de aceitação dos queijos deste experimento, foi utilizada uma escala hedônica estruturada de 9 pontos para os atributos aparência, cor, sabor e textura. Para avaliar a intenção de compra foi adotada uma escala hedônica estruturada de cinco pontos. Foi utilizado o modelo experimental de blocos completos casualizados, aplicados a cinquenta provadores não treinados. As amostras de $3 \mathrm{~cm} \times 3 \mathrm{~cm} \times 0,5 \mathrm{~cm}$ foram servidas em pratos plásticos codifcados à temperatura de refrigeração.

\section{RESULTADOS}

Todos os queijos de coalho com leite cru (QCC) obtiveram boa aceitação. Os maiores percentuais de aceitação concentram-se na nota 8, que corresponde, na escala hedônica, em "gostei muito". Também foi marcante a opção na nota 7 (gostei moderadamente) para o queijo QCC. O Queijo QCP obtve sua maior nota em "gostei ligeiramente” opção que corresponde a nota 4. A avaliação geral é um atributo importante por envolver uma impressão de todos os atributos sensoriais. Quanto ao índice de aceitabilidade, considera-se aceito o produto que alcançar no mínimo $70 \%$. Como pode ser obserado na figura 1 , os queijos QCC não tiveram rejeição, enquanto que o QCP apresentou uma porcentagem de $20 \%$ de rejeição. Esse dado nos preocupa, uma vez que este tipo de queijo é mais seguro para a saúde da população do município de Currais Novos. 


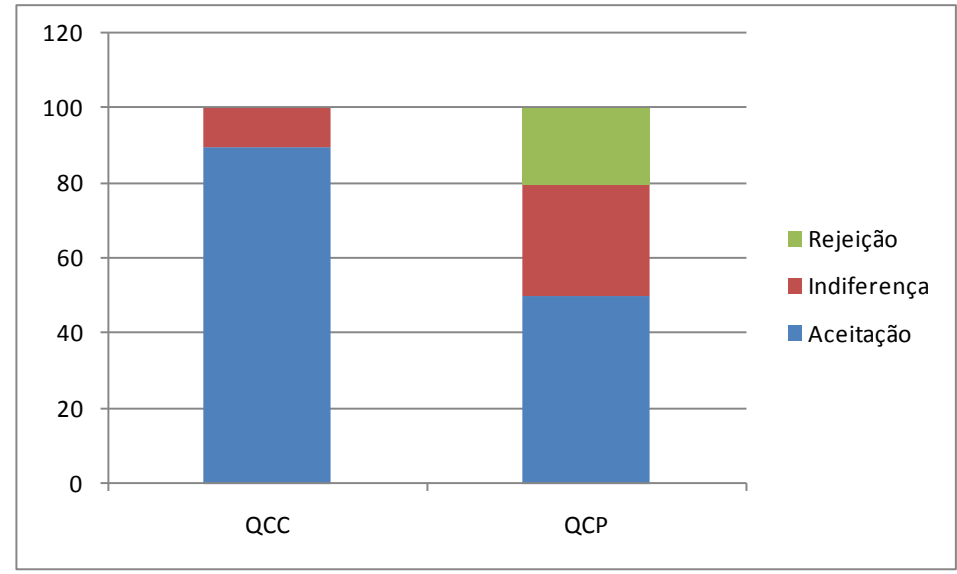

Figura 1. Índice de aceitabilidade da avaliação dos queijos de coalho

Na figura 2, podemos observar que todos os queijos QCC obtiveram média superior a 70\%, enquanto que todas as marcas dos queijos QCP não alcançaram o mínimo exigido de $70 \%$ de aceitação, ficando no máximo duas marcas com 60\% (QCP1 e QCP5). Esse dado nos leva a inferir que o hábito cultural do queijo tradicional é superior ao apelo do consumo de produtos pasteurizado, indicando que há uma necessidade de trabalho educativo e de saúde pública intensa junto à população.

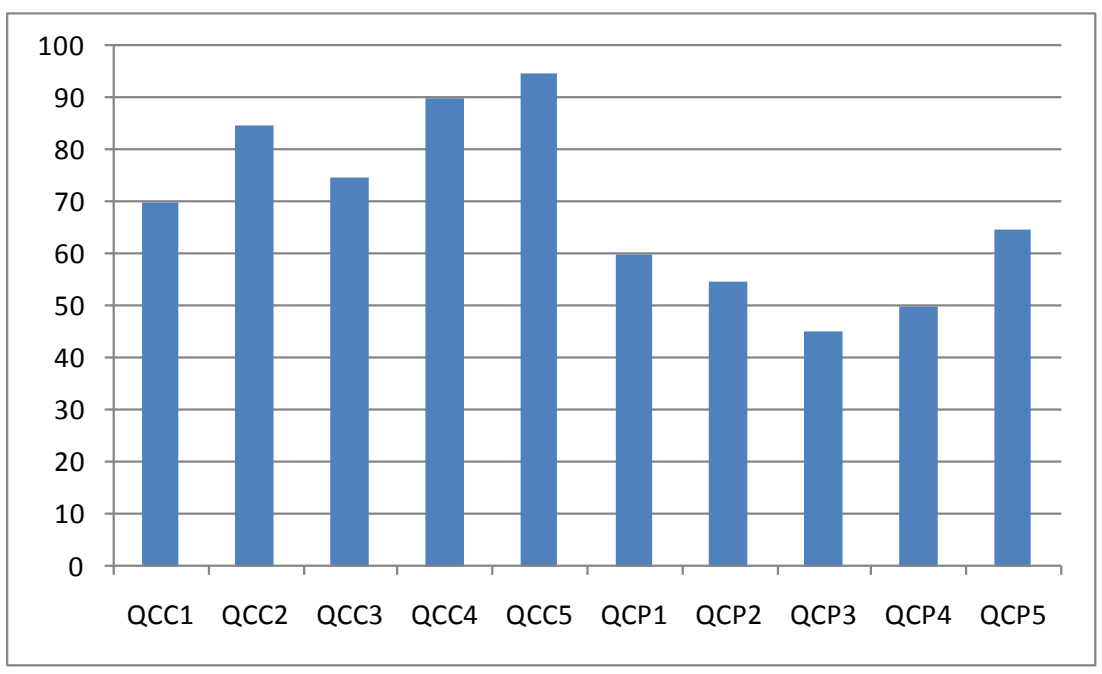

Figura 2. Frequencia da avaliação de todos os queijos de coalho usados na análise

Na Figura 3 está demonstrado o histograma de freqüência da intenção de compra dos queijos de coalho. Os resultados da intenção de compra reforçam de certa forma, a aceitabilidade e preferência dos produtos QCC. O QCC1 obteve o maior percentual de intenção de compra. A maioria dos provadores marcou as notas 4 (possivelmente compraria) e 5 (compraria) para o produto QCC, respectivamente. O queijo QCP5 foi o único que obteve um percentual significativo. É intensão no futuro de fazer uma caracterização da microbiota deste tipo (QCP5), com uma análise molecular do 16S ribossomal e comparar com a microbiota do queijo de coalho QCC5, que foi o mais aceito, 
para uma padronização e melhoria do sabor do queijo de coalho pasteurizado, produzido no município de Currais Novos e região do Serido.

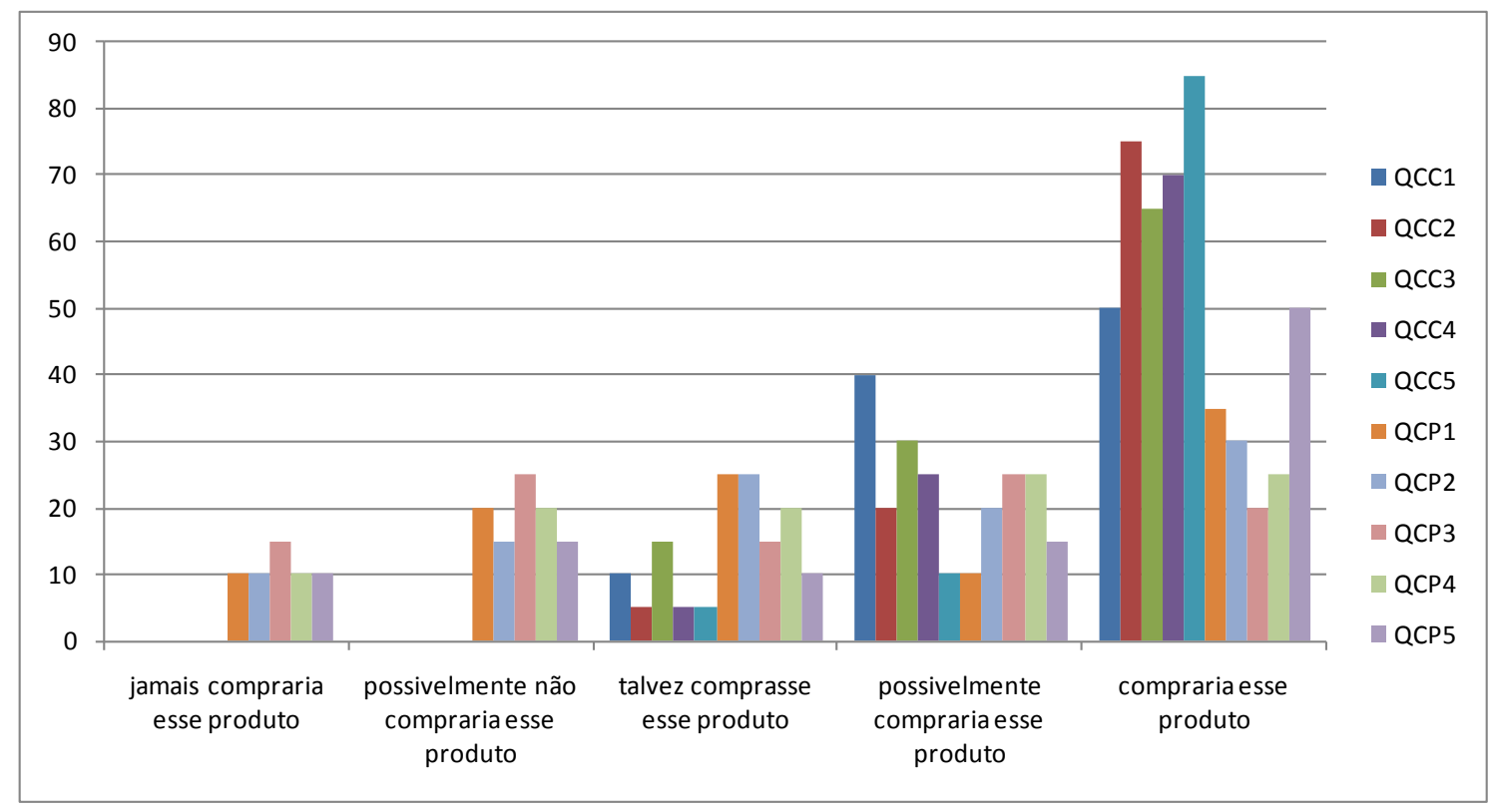

Figura 3. Frequencia de intensão de compra dos queijos de coalhos.

\section{CONCLUSÃO}

Todos os queijos de coalho feitos com leite cru (QCC) obtiveram boa pontuação na avaliação, enquanto que os queijos de coalho feitos com leite pasteurizado (QCP), não alcançaram o índice mínimo de aceitação, indicando a necessidade urgente de um trabalho de conscientização e esclarecimento junto a população de Currais Novos/RN.

\section{REFERÊNCIAS BIBLIOGRÁFICAS}

BRASIL. Ministério da Agricultura, Pecuária e Abastecimento. Inst. Normativa $\mathrm{N}^{\circ}$ 30, de 26 de junho de 2001. Regulamentos Técnicos de Identidade e Qualidade de Queijo de Coalho. Diário Oficial da União Federativa do Brasil, Brasília, DF, 16 jun 2001, Seção 1, 13 p.

CAVALCANTE, J. F. M. Sistema de apoio á decisão na produção de leite e queijo coalho com segurança alimentar. 2005. 158f. Tese (Doutorado em Ciência e Tecnologia de Alimentos) - Departamento de Tecnologia de Alimentos, Universidade Federal de Viçosa, Viçosa.

CAVALCANTE, J. F. M.; ANDRADE, N. J.; SILVA, R. F. N. Valorização do queijo de artesanal brasileiro: caso do queijo de coalho. Rev. ILCT, Juiz de Fora, v. 59, n. 339, p. 215-18, jul./ago. 2004.

ESCOBAR, C. A. M. et al. Avaliação dos pontos críticos na produção de queijo de coalho em Pernambuco. Rev. ILCT, Juiz de Fora, v. 56, n. 321, p. 248-256, jul./ago. 2001. 
JACK, F. R., PATERSON, A. \& PIGGOTT, J. R. 1993. Relationships between rheology and composition of Cheedar cheeses and texture as perceived by consumers. Int. Journal of Food Science and Technology, 28: 293-302.

LEITE, C.C.; GUIMARÃES, A.G.; ASSIS, P.N.; SILVA, M.D.; ANDRADE, C.S.O. Qualidade bacteriológica do leite integral (tipo C) comercializado em Salvador-BA. Revista Brasileira de Saúde Pública, n.3, v.1, p.21-25, 2002.

MUNCK, A.V. Queijo de coalho - Princípios básicos da fabricação. Rev. ILCT - Anais do XXI Cong. Nac. de Laticínios, Juiz de Fora, v. 59, n. 339, p.13-15, jul./ago. 2004.

PINHEIRO, C. M. S. C. 2001. Contributo para a Caracterização do Queijo de Ovelha produzido na região de Évora: Aspectos químicos bioquímicos do leite obtido em diferentes sistemas de produção e físico-químicos, bioquímicos, tecnológicos e organolépticos do queijo. Tese de doutoramento. Universidade de Évora, Évora, Portugal. SCHIMITT, A.; DURR, J.W.; SOARES, J. Efeitos da estação do ano sobre a flora bacteriana do leite cru. 2007. Disponível em: <http://www.upf.br/pesquisa>.

SOUSA, D.D.P. Consumo de produtos lácteos informais em Jacareí-SP. São Paulo, 2005. 114 f. Dissertação (Mestrado) - Departamento de Medicina Veterinária Preventiva e Saúde Animal, Universidade de São Paulo. 